\title{
As consequências do processo de desterritorialização da pesca artesanal na Baía de Sepetiba (RJ, Brasil): um olhar sobre as questões de saúde do trabalhador e o ambiente
}

\author{
Deterritorialization of artisanal fisheries in Sepetiba Bay \\ (State of Rio de Janeiro, Brazil): an overview \\ of occupational health and environmental issues
}

Marcelo Bessa Freitas ${ }^{1}$

Silvio Cesar Alves Rodrigues ${ }^{2}$

${ }^{1}$ Escola Nacional de Saúde Pública, Saneamento e Saúde Ambiental. R. Leopoldo Bulhões 1480, Manguinhos. 21.041-210 Rio de Janeiro RJ. bessa@ fiocruz.br

${ }^{2}$ Instituto de Pesquisa e Planejamento Urbano e Regional, Universidade Federal do Rio de Janeiro.

\begin{abstract}
This paper outlines the consequences of deterritorialization of artisan fishing folk in Sepetiba Bay in the State of Rio de Janeiro on the occupational and health status of this population living in the area. By means of the concept of social determinants in health, it compares the new patterns of growth in the region with the living and occupational health conditions of these workers. This relationship was explained after conducting semi-structured interviews and focus groups. The results point to a strong relationship between the port undertakings and the installations of the nuclear program of the Brazilian Navy with subsistence and extractive fishing, contributing to an increase in the time spent at sea and the inherent occupational risks involved in subsistence fishing. This is in addition to the economic and environmental impacts on the productivity and quality of fishing production, which are a direct consequence of the dredging works and the new navigation and anchoring norms established and imposed by the state.

Key words Social determinants in health, Deterritorialization, Artisan fishing, Occupational health risks, Sepetiba bay
\end{abstract}

Resumo $O$ trabalho analisa as consequências da desterritorialização na Baía de Sepetiba sobre o processo de trabalho e saúde dos pescadores artesanais daquele território. Por meio do conceito de determinantes sociais em saúde, aproxima os novos vetores de crescimento da região com as condições de vida e saúde destes trabalhadores. Através de entrevistas semiabertas e grupos focais explicitou-se esta relação. Os resultados sugerem uma forte associação entre os empreendimentos portuários e as instalações do programa nuclear da Marinha do Brasil com a pesca extrativa tradicional, contribuindo para o aumento do tempo de navegação e dos riscos ocupacionais inerentes à pesca artesanal. Além dos impactos econômicos e ambientais na produtividade e qualidade do pescado, consequência direta das obras de dragagem $e$ dos novos fluxos de navegação e fundeio estabelecidos e impostos pelo estado.

Palavras-chave Determinantes sociais da saúde, Desterritorialização, Pesca artesanal, Riscos ocupacionais, Baía de Sepetiba 


\section{Introdução}

As atividades extrativas, inseridas e fortemente relacionadas aos ecossistemas que dão suporte à reprodução do trabalho, tais como agricultura familiar, extração vegetal e a pesca artesanal, estão sujeitas a uma escala maior de vulnerabilidade frente aos diferentes tipos de impactos e danos ambientais, sobretudo, nos espaços determinados pela soma de interesses econômicos e políticos, convertidos em alvos de apropriação e refuncionalização produtiva.

Nestes lugares as reconfigurações socioeconômicas projetadas afinam-se com o processo de desterritorialização ${ }^{1}$, como efeito, forjam-se novas relações de poder ao distanciar o trabalhador do seu processo produtivo. A operação tem incidência direta sobre as populações tradicionais e frequentemente aciona dispositivos dificultadores das práticas e costumes laborais enraizados. Enquanto impõe inexoravelmente perdas dos elementos simbólicos que ajudaram a modelar identidades, inibem a transmissão de valores socioculturais e provocam movimentos que processualmente avigoram o arrefecimento da memória coletiva. Além disso, contribui para o aumento de tensões psicossociais e riscos ocupacionais, inerentes às atividades extrativas, $\mathrm{o}$ que potencializa agravos à saúde. Considerando, principalmente o processo de adoecimento dos indivíduos, no que tange às enfermidades crônicas não transmissíveis, transcorrer da reprodução social no meio em que se vive e trabalha.

Compreender tais transformações, particularmente nos territórios de ecossistemas marinhos, implica no reconhecimento de que os processos de trabalho associados a tais espaços produtivos, em particular da pesca artesanal, estão sujeitos a assumir outras funções ou configurações diferentes das historicamente construídas. As principais consequências do "novo" contexto socioeconômico e produtivo, imposto por agentes públicos e privados, radicalizam o esmaecimento da atividade extrativa e o enfraquecimento dos arranjos produtivos locais associados à pesca artesanal. Sendo assim, a determinação social das doenças associadas à atividade produtiva estaria na dependência do grau e magnitude da refuncionalização e reconfiguração desses territórios.

A hipótese transporta o pensamento crítico no âmbito das representações, no contexto de uma espécie de "simbiose" constituída pela interação entre indivíduos e meio suporte, materializada na obtenção de recursos para subsistência e manutenção dos arranjos produtivos, reprodu- tores de significados e significantes "do" e "no" espaço social. Compreendido como um conjunto de formas representativas de relações sociais, manifestadas em processos e funções. Fazendo-se necessário recordar que no locus de convivência se desenvolvem práticas, hábitos e subjetividades².

Desta forma, remetemo-nos aos arranjos espaciais que se substantivam como a instância onde flutuam e se articulam sujeitos, tecnologias e estrutura. Nexo das interações entre diversos elementos, onde se origina um sistema conjugado de dimensões econômicas, sociais e culturais. Nesta acepção, a disputa pela apropriação dos espaços se projeta no sentido de construir novas feições territoriais, ou seja, territorialidades, observadas na perspectiva de um conjunto de ações, comportamentos individuais ou de grupos que procuram influenciar e controlar pessoas, fenômenos e relações. Para tanto, combinam representações sociais e práticas espaciais, catalisando grandezas psicológicas, sociais e políticas no objetivo de constituir um amplo espectro de compreensões referentes ao plano locacional, na formação de atores e de agentes ocupados em compor possíveis arranjos e/ou estruturas, incluídas no domínio da ação social no território. Marcando o cenário com a dinâmica da disputa, apropriação e deslocamentos, fundamentais nos processos de desterritorialização e reterritorialização ${ }^{1,3,4}$.

Assume-se desse modo, que o processo de desterritorialização inicia-se na tentativa de isolar o território das suas "raízes" sociais e culturais ${ }^{5}$. Analogamente, o procedimento pressupõe a "limpeza do terreno", atuando sobre porosidades com o objetivo de calafetar os traços e elementos constituidores de vínculos solidários, recíprocos e aglutinadores. Por sua eficácia na tarefa de confiscar conteúdos e bens relacionais, conformadores de identidades entre indivíduos e território, a desterritorialização se afirma como importante estratégia, a fim de conter, restringir, destituir e excluir categorias, grupos e indivíduos de sua relação material e subjetiva com este mesmo território.

Ao fim da expropriação ou destituição de referenciais, o território esvaziado de suas células principais, forjadas por relações entre semelhantes e diferentes torna-se estéril ou híbrido, sem oferecer resistência à reterritorialização, ou seja, apto à instrumentalização com poder para desenhar a (re)apropriação dos espaços físicos e simbólicos ${ }^{3}$. A empreitada se completa com a caricatura de paisagens, exerces, usanças e tramas a fim de produzir outros sentidos e introjetar novas compreensões. A missão principal deste movimento, baseado na diluição das relações e vín- 
culos sociais, é sobrepor "a economia de afetos"6 para artificialmente reconstruir e ressignificar o território, cinzelando um "não lugar", investido na realização das "não identidades" - sobrepondo o lugar dos antigos espaços de convivência -, isso tudo sem desprezar a distribuição da exclusão social através de danos, perdas e possibilidades de adoecimentos.

Considerando o pressuposto do adoecer na pesca, interpretamos e readaptamos o modelo proposto por Dahlgren e Whitehead ${ }^{8}$ para observar o processo de "des" e reterritorialização como uma função dos determinantes sociais na saúde e no trabalho dos pescadores artesanais. Vários modelos conceituais já foram elaborados e empregados a fim de compreender melhor os nexos causais relacionados às doenças crônicas não degenerativas como as do âmbito ocupacional. Desde a teoria do estresse de James Cassel e a do capital social e desigualdades, ambas influenciadas pela sociologia funcional norte-americana, até os modelos materialistas histórico do adoecimento, como resultado das lutas de classes e do processo de trabalho e modo de reprodução social, todos buscaram a confecção de esquemas e modelos explicativos dos modos crônicos ou agudos de adoecimento. Mas, recentemente, vem sendo reconhecida a necessidade de incorporar a esta análise, diferentes abordagens a fim de ampliar essa compreensão, tendo em vista a complexidade do processo saúde-enfermidade. Neste sentido, abordagens influenciadas pelas teorias e conceitos da semiologia, do simbólico e da hermenêutica vêm adquirindo um status teórico complementar nos modelos explicativos e narrativos sobre o conjunto de doenças não transmissíveis ${ }^{9}$.

Dahlgren e Whitehead ${ }^{8}$ evidenciam cinco níveis interdependentes (Figura 1) que atuam direta e indiretamente sobre o processo saúdedoença de grupos e indivíduos. No nível mais externo desse modelo, estão os macrodeterminantes representados pelas condições socioeconômicas, culturais e ambientais gerais; no nível subsequente os determinantes intermediários como função das condições de vida e de trabalho, representados pelo acesso aos serviços públicos, educação, habitação, saneamento, saúde, produção de alimentos, emprego e renda. A partir deste nível estão os determinantes associados aos estilos de vida individuais, situados na fronteira dos microdeterminantes sociais, compreendidos por fatores hereditários, idade e gênero. Segundo os autores, a compreensão do processo saúde-doença decorre da análise dos micro e macro determinantes e suas formas de correlação e mediação, atribuindo ao contexto social as chamadas doenças não transmissíveis, como as que se relacionam ao âmbito ocupacional ${ }^{10-12}$. Na con-

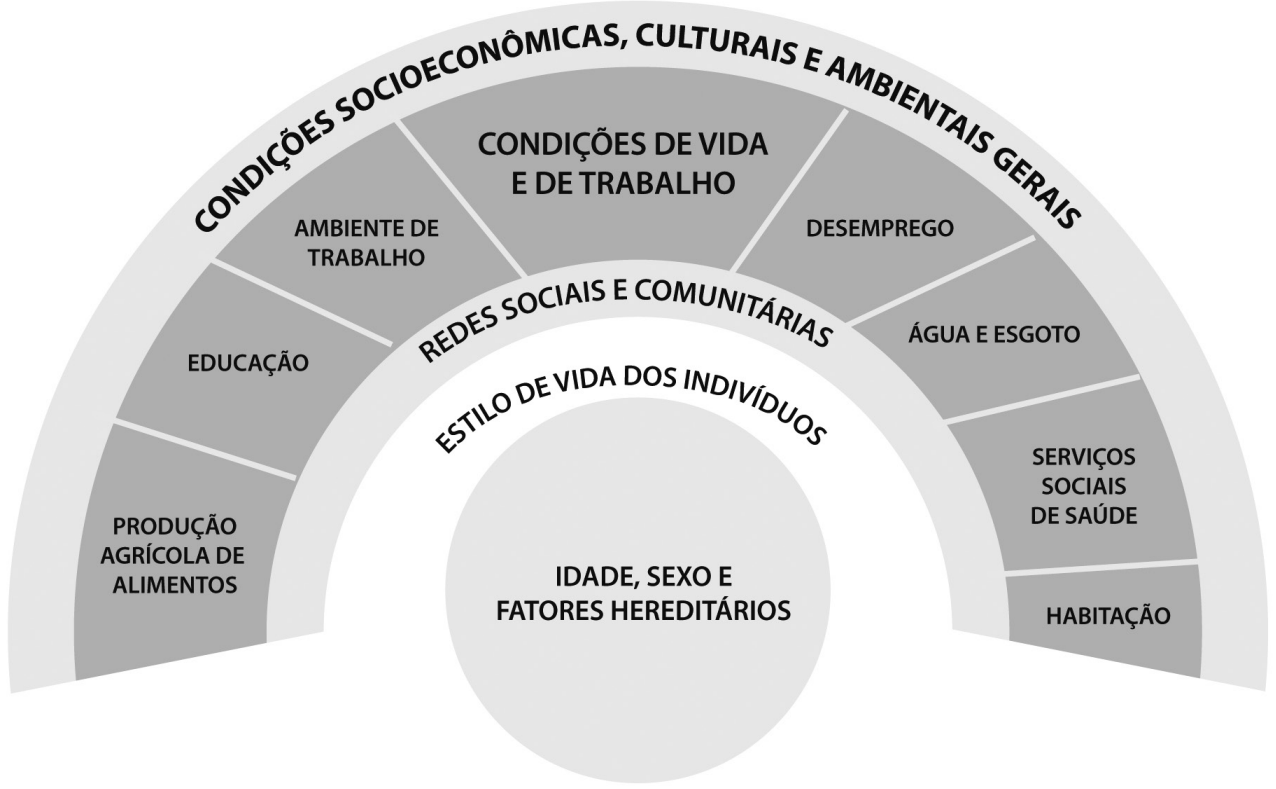

Figura 1. Modelos de determinação social da saúde, segundo Dalhgren e Whitehead ${ }^{8} \mathrm{e}$ adaptado pela Comissão Nacional sobre Determinantes Sociais da Saúde ${ }^{13}$. 
dução metodológica do estudo, procurou-se uma maior aproximação a este modelo, proposto pela Comissão Nacional de Determinantes Sociais da Saúde ${ }^{13}$, como estratégia para a formulação de políticas de saúde diante do processo saúde-doença da população. Partimos do pressuposto que as condições socioeconômicas, culturais e ambientais são determinadas no contexto da desterritorialização. Para isto, é fundamental assumir que este processo afetará as condições de trabalho e saúde do pescador artesanal em uma relação espaço-temporal ditada pela função do ritmo da "des" e reterritorialização, porém dependentes do nível de influência e implicação das redes sociais, associações e colônias, no enfrentamento das adversidades, associadas à "deslocalização" e perdas de espaços tradicionais de atividades extrativas daquele território (Figura 2).

$\mathrm{O}$ estudo centralizou seu recorte no sistema hidrográfico da Baía de Sepetiba, estado do Rio de Janeiro, a qual possui aproximados $305 \mathrm{~km}^{2} \mathrm{e}$ abrange três municípios, a zona oeste do perímetro urbano da capital do Estado, e os municípios de Itaguaí e Mangaratiba. Considerando toda a área de influência, o sistema abrange 11 municípios, onde vivem 467.046 habitantes em áreas urbanas e 41.709 habitantes em áreas rurais, com uma densidade populacional de $180,4 \mathrm{Hab} / \mathrm{Km}^{2}$. É neste território que os poderes de Estado, através de sua política econômica, vem catalisando um maior fluxo de capitais externos, o que tem estimulado um padrão de crescimento econômico acelerado, baseado principalmente em commodities minerais. A estratégia de intervenções reconfiguradoras visa às instalações logísticas,

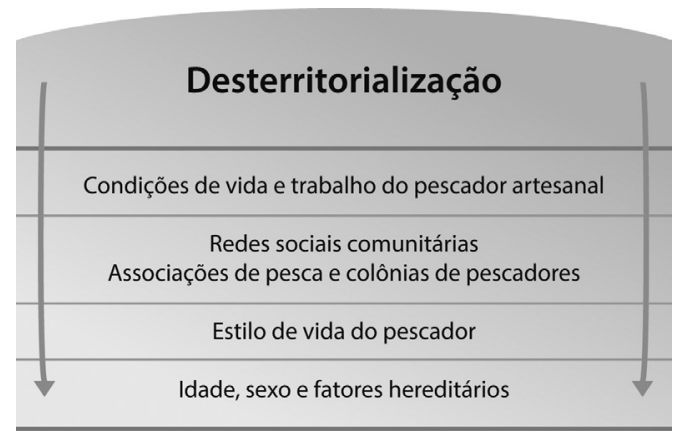

Figura 2. Modelo de determinantes sociais da saúde, adaptado de Dalhgren e Whitehead ${ }^{8}$ para o contexto da pesca artesanal na Baía de Sepetiba. industriais e portuárias, provocando intensas e significativas transformações estruturais e paisagísticas, materializando novas conjugações de fluxos, base de sustentação para uma economia de exportações do setor primário com efeitos negativos sobre aspectos tangíveis e intangíveis.

\section{A Pesca Artesanal no Brasil}

A pesca artesanal, como atividade econômica, surgiu no Brasil a partir da falência da economia dos ciclos cafeeiro e açucareiro do período colonial e da necessidade de se explorar outros meios que não fossem a coleta extrativa e a caça continenta ${ }^{14}$. A pesca artesanal se caracterizou como economia fundamental na manutenção dos arranjos produtivos locais de modo extrativo, tanto nos ecossistemas litorâneos como nos fluviais do território brasileiro. Posteriormente, reconhecidos pela importância geoestratégica (vigilância e ocupação), os trabalhadores da pesca afirmaramse nos espaços litorâneos através da constituição das colônias de pesca, após 1919, por obra da Marinha de Guerra. As colônias receberam a denominação composta pela letra "Z" e uma grandeza numeral (Z-1, Z15, Z-16), junto ao lema positivista "Pátria e Dever", sob o discurso da defesa nacional e a convicção de os pescadores serem os melhores conhecedores dos "segredos" do mar ${ }^{15}$.

Por definição, pesca artesanal é aquela que na captura e desembarque de toda classe de espécies aquáticas, os trabalhadores atuam sozinhos e/ou utilizam mão de obra familiar ou não assalariada, explorando ambientes ecológicos localizados próximos à região costeira, com embarcações de baixa autonomia. A captura é feita através de técnicas de reduzido rendimento relativo e sua produção é total ou parcialmente destinada ao mercado ${ }^{16}$.

Segundo o $\mathrm{Ibama}^{17}$, a pesca extrativa marinha (que inclui a artesanal e industrial), movimentou, em 2007, no estado do Rio de Janeiro um volume de $82.528,5$ toneladas, incluindo peixes, moluscos e crustáceos, tornando o estado o maior produtor de pescado da região sudeste e o segundo do Brasil, ficando atrás apenas do estado de Santa Catarina. Neste mesmo ano, o estado registrou um crescimento na produção de pescado de $23,3 \%$, e essa produção arrecadou $\mathrm{R} \$$ 216.871.670,00, com relação ao ano anterior. No período destacado a pesca artesanal foi responsável pela produção de $20.636,5$ toneladas de peixes, crustáceos e moluscos, alcançando $25 \%$ da produção nacional, com faturamento bruto de $\mathrm{R} \$ 62.839 .289,00$ ou $28,97 \%$ do valor total pro- 
duzido. Deste volume de pescado, o modo artesanal foi responsável pela captura de $23,77 \%$ de peixes, $80 \%$ de crustáceos e $18,70 \%$ de moluscos.

Os levantamentos oficiais, fornecidos pelo Ministério da Pesca e Aquicultura (MPA), Secretaria de Estado Desenvolvimento Regional Abastecimento e Pesca (Sedrap) e Fundação Instituto de Pesca do Estado do Rio de Janeiro (FIPERJ) são frequentemente permeados por lacunas e intermitências que inviabilizam análises contínuas e precisas das séries históricas, tanto em relação à produção pesqueira quanto ao efetivo de pescadores e embarcações ativos na região. Portanto, os dados oficiais sobre a quantidade e a qualidade do pescado capturado na Baía de Sepetiba apresentam, em geral, pouca consistência analítica e imprecisões. Sendo assim, as informações mais precisas sobre esta realidade são obtidas de forma complementar por registros, quando existentes, das colônias e associações de pesca, e também por meio de pesquisas acadêmicas. Em um levantamento realizado, desde o ano de 2006, pelo Mapa de Conflitos Envolvendo Injustiça Ambiental e Saúde no Brasil apontou a existência de cerca de oito mil pescadores artesanais, ameaçados pela degradação ocasionada por empreendimentos industriais e portuários na Baía de Sepetiba ${ }^{18}$.

Em 2006, a Secretaria Especial de Aquicultura e Pesca da Presidência da República (SEAP/PR) divulgou a existência de 390.761 mil pescadores artesanais registrados no país. Em 2011, o Ministério da Pesca e Aquicultura apresentou em seu relatório anual o total de 957 mil pescadores artesanais registrados ${ }^{19}$, portanto, um aumento de aproximadamente $244 \%$. A não convergência de dados sobre o contingente total de pescadores ou mesmo o aumento abrupto desse universo em um período de apenas cinco anos, produzidos por diferentes atores e iniciativas nos obriga a considerar a necessidade de universos amostrais e recortes mais precisos a respeito desta categoria, evitando assim inferências poucos precisas, quando análises mais estendidas e representativas forem tomadas.

No levantamento realizado pela presente pesquisa foram aferidos, no total, 1676 pescadores lotados nas três colônias que abrangem a área geográfica da Baía de Sepetiba, a Z4 (Guaratiba), Z15 (Sepetiba) e Z16 (Mangaratiba), entre 323 mulheres e 1353 homens cadastrados nessas colônias. Este número absoluto foi obtido a partir da contagem das fichas de registro dos pescadores associados em cada uma das colônias, adimplentes e inadimplentes com as taxas de associação, porém, todos ativos.

\section{Determinantes sociais da saúde do trabalho na pesca artesanal}

A Organização Internacional do Trabalho (OIT) refere-se à pesca como uma das mais desgastantes e perigosas atividades desenvolvidas pelo homem. Vários estudos apontam para os aspectos relacionados à segurança e saúde do trabalhador do setor da pesca ${ }^{20-26}$.

Oficialmente, os pescadores artesanais se organizam como classe a partir da criação, em 1950, pelo Governo Federal, da Confederação Nacional dos Pescadores (CNP), da Federação Estadual dos Pescadores (FEPAS) e definitivamente das colônias de pesca. Este sistema confederativo se fixou na jurisdição do Ministério da Agricultura, que definiu os estatutos básicos para existência das colônias de pescadores, mas sem apresentar condições que legitimassem o exercício representativo e autônomo ${ }^{27}$.

A partir de 2008 a categoria foi reorganizada em temos da Lei no $11.699^{28}$, que dispõe sobre as Colônias, Federações e Confederação Nacional dos Pescadores. Através do instrumento normativo, essas entidades se tornaram reconhecidas como órgãos de classe dos trabalhadores do setor artesanal da pesca, com forma e natureza jurídica próprias, obedecendo ao princípio da livre organização previsto no art. $8^{\circ}$ da Constituição Federal $^{29}$.

Apesar da Lei, a realidade expõe um quadro relevante de precarização do acesso ao sistema previdenciário e de seguro social, o que contribui para o aumento da informalidade e exclusão social da categoria ${ }^{23}$. Em se tratando de uma atividade onde os riscos à saúde são inerentes a um processo de trabalho extenuante e extremamente informal, sem proteção e garantias trabalhistas, a situação de exposição aos riscos e ocorrências de danos ocupacionais se agrava.

Observando os processos de trabalho de pescadores artesanais, diversos estudos ${ }^{22-25}$ afirmam que a atividade está exposta à intensa radiação solar, intempéries, baixa luminosidade devido ao trabalho noturno, acidentes com apetrechos da pesca e animais com potencial de ocasionar cortes e perfurações, ruídos contínuos de motorização, afogamentos e sobrecarga de peso, que podem levar ao afastamento da atividade por dias ou meses. Soma-se ao quadro, a inexistência de instalações sanitárias nas embarcações de médio porte, como por exemplo, as traineiras, o que contribui para o aumento do desconforto a bordo. Situações vivenciadas pelos pescadores, naturalizadas no cotidiano de trabalho e expressas em relatos 
que afirmam "o pescador está acostumado" ${ }^{24}$. Há ainda nesse processo de trabalho um forte componente psicossocial de sofrimento e estresse vinculado à baixa produtividade da pesca, ao afastamento da família e a casos de violência e criminalidade no mar $^{26}$.

\section{Método}

Com o intuito de adaptar a análise em função do esquema proposto por Dahlgren e Whitehead ${ }^{8}$, a condução do estudo optou por uma abordagem qualitativa do objeto. Por conseguinte, a investigação foi dividida em duas fases, utilizando instrumentos distintos de coleta de dados e informações. A metodologia empregada na pesquisa de campo foi aprovada na avaliação do comitê de ética da Escola Politécnica de Saúde Joaquim Venâncio/Fundação Oswaldo Cruz, atendendo à Resolução 196/96³.

A pesquisa qualitativa envolveu entrevistas semiabertas e grupos focais como forma de apreender, a partir dos atos de fala dos pescadores artesanais, conteúdos fundamentais que envolvessem os problemas sociais, políticos e ambientais associados ao processo de reconfiguração e refuncionalização do território por meio de suas percepções, atitudes e representações sociais existentes.

Durante o trabalho de campo, realizado entre 2011 e 2012, procurou-se manter encontros frequentes com os sujeitos da pesquisa, o que contribuiu para o reconhecimento de suas realidades. Este procedimento permitiu uma maior aproximação aos significados, sistemas simbólicos, códigos, práticas, valores, atitudes, ideias e sentimentos que constituem fenômenos não reduzidos à operacionalização de variáveis exatas ${ }^{31}$. Argumento substancial para empreender a análise das relações sociais entre a práxis e o contexto histórico daquele território.

Recorreu-se a três encontros para a realização dos grupos focais, envolvendo em cada grupo cinco convidados representantes de cada uma das três colônias de pescadores locais (Z14 - Guaratiba, Z15 - Sepetiba e Z16 - Itacuruçá), entre julho e outubro de 2012. Para os grupos focais foram utilizados um guia de entrevistas, reunindo questões e estímulos narrativos, centralizados no problema e orientados pelo objeto e processo da pesquisa $^{32}$. As seguintes questões e estímulos narrativos foram utilizados durante os grupos focais: a) o que você pensa sobre os sobre os empreendimentos existentes na região da Baía de Sepetiba; b) como você vê a relação entre os pescadores, entre os pescadores e o poder público, e entre os pescadores e as empresas instaladas na região; c) em sua opinião, como está o meio ambiente na Baía de Sepetiba; d) você acha que isso afeta a sua saúde? Sim ou Não e Por quê? E, e) Como você vê o futuro da sua região?

A alternativa metodológica proposta reconhece o desafio de identificar possíveis mediações existentes entre os diferentes fatores de natureza social, econômica, política, os quais, dentro da perspectiva da determinação social, incidiriam sobre a situação de saúde de grupos e pessoas. Porém, é através do conhecimento desse complexo de mediações, que se permite uma melhor compreensão a respeito de correlações entre macro indicadores de riqueza de uma sociedade, por exemplo o PIB, e os indicadores de saúde, não necessariamente se comportarem de modo constante e linear ${ }^{33}$.

As mediações entre camadas de determinantes e condicionantes da saúde dos grupos populacionais localizados em um determinado território podem apresentar vetores de sentidos coincidentes ou contraditórios. Por exemplo, o investimento na criação de terminais portuários para escoar a produção de commodities minerais é um vetor positivo no nível global/nacional, entretanto no nível local, na medida em que dificulta ou inviabiliza a realização de atividades ligadas aos arranjos produtivos locais na pesca artesanal pode ser compreendido como vetor negativo.

\section{Resultados}

Os resultados da nova reconfiguração e refuncionalização do território da Baía têm como principais consequências os impactos socioambientais no ecossistema litorâneo, além do recrudescimento de problemas relacionados à saúde do trabalhador da pesca. Argumentos que apontam para estas evidências foram encontrados nos depoimentos dos pescadores partícipes dos grupos focais, e para efeito prático optou-se por destacar algumas dessas narrativas.

Os novos empreendimentos na Baía de Sepetiba, sinalizados como macrodeterminantes, são representados em sua totalidade pelas obras de ampliação do Porto de Sepetiba, instalação da ThyssenKroupp Companhia Siderúrgica do Atlântico, do Porto Sudeste MMX (setor de logística do grupo EBX) e do Programa de Desenvolvimento de Submarinos - Estaleiro e Base Naval (PROSUB-EBN). No contexto de desterritoriali- 
zação, novos fluxos de circulação são definidos e impostos por agentes públicos, como a Capitania dos Portos e o órgão de controle ambiental do estado do Rio de Janeiro, o INEA ${ }^{34}$. É neste sentido que alguns depoimentos destacam essa deslocalização.

... não precisávamos ir tão longe pra pegar o peixe, que nós saíamos aqui perto, em frente e já conseguíamos, mas o que ocorre de um tempo pra cá é que os grandes empreendimentos se instalaram na nossa baía e esse empreendimento causou várias restrições na nossa área de pesca... Pescador 1

Seguindo assim no continuum de se impor uma nova territorialidade, se estabelecem novas restrições aos antigos fluxos de navegação às embarcações tradicionais de pequeno porte, utilizadas na pesca artesanal, como as traineiras e canoas. Potencializando dessa forma, acidentes com óbitos, associados ao aumento do tráfego marítimo das embarcações de grande calado, como os conteineiros e graneleiros, percebidos na seguinte narrativa:

... têm as boias, o pescador respeita, só que eles não respeitam. Esse ano [2012] mataram um pescador em Coroa Grande. É, porque veio outro, veio pelo lado... Um navio no canal e do outro lado chegou outro...Pra mim foi um crime, porque eles sabem que não podia ta andando daquele jeito... Pescador 8.

E neste processo produtivo evidencia-se a agudização do desgaste físico no trabalho, a iniquidade em saúde promovida por uma hipertrofia associada a uma fadiga psicológica e social. Para Laurell e Noriega ${ }^{35}$ este desgaste seria uma resultante do próprio processo de produção no qual o pescador está inserido, revelando um tipo de nexo biopsíquico, identificado pelos autores como manifestação intrínseca à corporeidade humana dos processos históricos gerais.

... você vai ter que sair mais cedo. Então passo mais, mais tempo, um cansaço físico, um cansaço mental, quer dizer você vai mais longe, o cansaço físico ainda pra você que você vai pegar um sol entendeu, você vai ter mais raio de sol em você... Pescador 9

Atos de fala que sinalizam a degeneração do ecossistema da baía estão associados às constantes dragagens, com o objetivo de aprofundar canais de acesso para o trânsito das grandes embarcações, efetuadas nas proximidades dos Portos de Sepetiba, Sudeste e EBN-PROSUB. Estas intervenções têm alterado significativamente a qualidade da água da baía, inviabilizando antigas práticas, ao se converterem em danos ambientais relevantes ${ }^{34}$.
... essa draga leva a lama, sabe, ela leva a lama de lá, pra lá. Mas aí ela não tem itinerário certo pra passar, entende, ela tem os canais dela passar, ela passa por um canal, às vezes passa fora do canal, aí está com rede lá que leva, é um abraço, se pegar aí pega rede, pega tudo ... Pescador 2.

O expediente revela a demasiada exploração daquele ecossistema. Na lógica produtivista a ampliação dos canais de acesso abriu o território à captura desenfreada de capitais, e a rotina de "sacrifício" desafia sua capacidade suporte, comprometendo a condição natural, seu equilíbrio e sua resiliência, valores inseridos na lógica sustentável e solidária dessa cadeia produtiva costeira. A chegada dos empreendimentos logístico-portuários e industriais - além de permitir a ressuspensão do material tóxico estabilizado no fundo da baía, decorrente dos sucessivos vazamentos dos tanques de resíduos industriais da extinta Companhia Industrial e Mercantil Ingá, falida na década de 1990, fez aumentar demasiadamente o trânsito de grandes embarcações e navios conteineiros, o que resultou em conflitos, entre pescadores e agentes públicos e privados, gerados por imposições aos novos fluxos de navegação, fundeio e atracação. Esse fato exigiu dos pescadores a busca por novas áreas de captura, no modo offshore, o que fez aumentar a competição desigual com embarcações que praticam a pesca predatória e industrial, vindas de outros estados e até mesmo de outros países.

Alguns entrevistados apontaram como um dos principais impactos ambientais da Baía de Sepetiba, a pesca predatória.

... vêm grandes embarcações de fora e chega aí e acaba com tudo... Tem a pescada que a gente não tem, porque vem as grandes traineiras, e não dá mais as anchova, a sororoca, peixes que davam antigamente, era abundante aqui agora não da mais, peixe tainha ou parati e esse camarão maluco que da aí de vez em quando... Pescador 5.

E nessa competição, se por um lado o estado se distancia do seu poder regulador e fiscalizador para com a pesca industrial, por outro, reforça e mantém esse papel diante da pesca artesanal, imprimindo um modus operandi intensamente rígido e assimétrico sobre as organizações e indivíduos que dependem diretamente da pesca artesanal. Perceptível nos seguintes depoimentos:

... é porque a pesca proibida e a pesca de balão são os grandes barcos que fazem e eles não respeitam ninguém, não tem fiscalização que segure eles ... Pescador 8 .

... a quem recorrer? Ah, é ao INEA aí vamos lá no INEA, o INEA pede uma série de documentos que nós não conseguimos ter... Pescador 3. 
A relação assimétrica que se impõe entre pescadores, Estado e empreiteiras da pesca conflagra um tipo de conflito socioambiental presente em praticamente toda a costa litorânea brasileira. Permeável à prática de modalidades pesqueiras pouco sustentáveis para os sistemas ecológicos existentes. Considerando as características das correntes marinhas e feições geomorfológicas e oceânicas desses ecossistemas litorâneos.

\section{Discussão}

Em consideração aos resultados obtidos, o quadro da pesca artesanal na Baía de Sepetiba aponta para uma condição de declínio ou estagnação, em um cenário menos pessimista. Essa projeção se fundamenta por meio das circunstâncias socioeconômica e ambiental, predominantes naquele território. A presença de externalidades negativas tais como a poluição ambiental, a competição com a pesca predatória e de grande porte, praticada ilegalmente na baía, assim como as alterações nos fluxos e locais de captura, impostos por novos arranjos políticos e econômicos, tem estimulado hábitos e práticas alternativas entre os pescadores artesanais.

A realidade dos novos fluxos contribuiu para alterar a rotina da pesca artesanal com implicações diretas sobre a produção pesqueira, uma vez que o processo restringe à navegação e captura de espécies, nos lugares reconhecidos e identificados pelos antigos pescadores como pesqueiros. A principal consequência econômica, ainda de acordo com os relatos, foi a queda na renda mensal das famílias, sobretudo aquelas que têm a pesca como principal fonte de subsistência.

Outra decorrência igualmente relevante, e diretamente associada, diz respeito às condições de vida e saúde. Uma vez que os novos arranjos econômicos implicam sobre as questões de segurança e saúde do trabalhador. Justamente por obrigá-lo a encontrar outros espaços e fluxos de navegação com a finalidade de manter a produtividade mínima condizente as suas necessidades de sustento. Portanto, o pescador se vê na necessidade de prolongar o tempo de trabalho, navegando por limites mais distantes do que os habituais, o que significa ampliar seu turno laboral, sujeitando-se assim, a uma maior exposição às situações de risco, intrínsecas à pesca artesanal e às modificações do espaço.

Neste cenário surge a oportunidade para o aumento dos casos de acidentes de trabalho inerentes à atividade, com bem explorado no mode- lo de determinantes sociais da saúde de Dahlgren e Whitehead ${ }^{8}$.

Substancialmente, a pesca extrativa artesanal, como internalidade contributiva, se situa à margem desse processo, uma vez que seu potencial é sempre subavaliado, considerando a quase nulidade de investimentos na manutenção, recuperação e proteção da Baía de Sepetiba como ecossistema suporte à produção da vida marinha.

Por fim, assim como foi corroborado por estudos anteriores ${ }^{21-26}$, conjugados com a devida manutenção dos condicionantes políticos e econômicos de motivação interna e externa, reiteramos a enorme vulnerabilidade socioambiental da atividade extrativa da pesca artesanal. Alerta-se, desse modo, para o enfraquecimento da prática tradicional, sobretudo, devido às dificuldades encontradas e "fraturas" expostas para seu desenvolvimento, guardando relação direta às implicações da poluição na baía e ao processo de desterritorialização e reterritorialização imposto pela parceria público-privada. Identificados como os principais macrodeterminantes econômicos a ter influência negativa no padrão ecológico suporte, mister ao trabalho extrativo, e subsequentemente, função da deterioração das condições de vida e saúde daquela população.

Além de provocar desequilíbrios no que tange aos recursos naturais, as atividades tradicionais tornaram-se vítimas contumazes, seja pela instalação das plantas físicas dos empreendimentos em lugares tradicionalmente reconhecidos como espaço da exploração de subsistência de baixa escala, como pela criação de áreas de exclusão, justificadas pela segurança do patrimônio das empresas, inclusive sob a alegação da prevenção da integridade física dos artesanais, compreensível diante do quadro atual. Essa interferência cria o que denominamos "arquitetura das grades", uma estrutura seletiva, tanto física quanto simbólica, com a função de controlar, e impedir acesso e circulação no espaço/território privatizado em busca de significados.

\section{Colaboradores}

MB Freitas trabalhou na concepção e na redação final do artigo; e SCA Rodrigues contribuiu com a pesquisa de campo, na metodologia e na redação final do artigo. 


\section{Referências}

1. Haesbaert R. O mito da desterritorialização: do fim dos territórios à multiterritorialidade. Rio de Janeiro: Bertrand Brasil; 2004.

2. Santos M. O espaço do cidadão. São Paulo: Nobel; 1987.

3. Guattari F. As três ecologias. Campinas: Papirus; 1993.

4. Raffestin C. Por uma geografia do poder. São Paulo: Ática; 1993.

5. Pagès $\mathrm{M}$, Bonetti $\mathrm{M}$, Gaulejac V, Descendre D. O poder das organizações: a dominação das multinacionais sobre os indivíduos. São Paulo: Atlas; 1987.

6. Elias N. O Processo civilizador. Rio de Janeiro: Zahar; 1990. Vol. 1.

7. Augé M. Não-Lugares: Introdução a uma antropologia da supermodernidade. São Paulo: Papirus; 1994.

8. Dahlgren G, Whitehead M. Policies and strategies to promote social equity in health. Stockholm: Institute for Future Studies; 1991.

9. Almeida-Filho N. Modelos de determinação social das doenças crônicas não-transmissíveis. Cien Saude Colet 2004; 9(4):865-884.

10. Solar O, Irwin A. A conceptual framework for action on the social determinants of health. Geneva: World Health Organization; 2007.

11. Samaja J. A reprodução social e a saúde. Salvador: Casa da Saúde; 2000.

12. Castellanos PL. Epidemiologia, saúde pública, situação de saúde e condições de vida: considerações conceituais. In: Barata RCB, organizador. Condições de vida e saúde. Rio de Janeiro: Abrasco; 1997. p. 31-75.

13. Comissão Nacional sobre Determinantes Sociais da Saúde (CNDSS). As causas sociais das iniquidades em saúde no Brasil. Rio de Janeiro: Editora Fiocruz; 2008.

14. Diegues ACS. Pesca e marginalização no litoral paulista [tese]. São Paulo: Universidade de São Paulo; 1973.

15. Diegues ACS. Pescadores, camponeses e trabalhadores do mar. São Paulo: Ática; 1983.

16. Clauzet M, Ramires M, Barrella W. Pesca artesanal e conhecimento local de duas populações caiçaras (Enseada do Mar Virado e Barra do Una) no litoral de São Paulo, Brasil. Revista Multiciência [periódico na Internet]. 2005 maio [acessado 2014 maio 29]; 4:1-22. Disponível em: www.multiciencia.rei.unicamp.br/artigos_04/rede_01_.pdf

17. Instituto Brasileiro do Meio Ambiente e dos Recursos Naturais Renováveis (Ibama). Estatística da pesca 2007. Brasil - grandes regiões e unidades da federação. Brasília: Ibama; 2007.

18. Fundação Oswaldo Cruz (Fiocruz). Mapa de Conflitos Envolvendo Injustiça Ambiental e Saúde no Brasil. 2006 maio [acessado em 2014 maio 29]. Disponível em: http://www.conflitoambiental.icict.fiocruz.br/index. php?pag=ficha\&cod=109>

19. Brasil. Ministério da Pesca e Agricultura (MPA). Pesca artesanal. 2011 Agosto [acessado em 2014 maio 29]. Disponível em: http://www.mpa.gov.br/pescampa/artesanal

20. Bezerra BPA. Saúde mental no nordeste da Amazônia: estudo de pescadores artesanais [tese]. São Paulo: Escola Paulista de Medicina; 2002.
21. Dall'Oca AV. Aspectos socioeconômicos, de trabalho e de saúde de pescadores do Mato Grasso do Sul [dissertação]. Corumbá: Universidade Federal de Mato Grosso do Sul; 2004.

22. Garrone Neto D, Cordeiro RC e Haddad JRV. Acidentes do trabalho em pescadores artesanais da região do Médio Araguaia, Tocantins, Brasil. Cad Saude Publica 2005; 21(3):795-803.

23. Brasil SS. Trabalho, adoecimento e saúde: aspectos sociais da pesca artesanal no Pará [dissertação]. Belém: Universidade Federal do Pará; 2009.

24. Gonçalves EG, Nogueira LSM, Brasil SS. Segurança e saúde dos pescadores artesanais no estado do Pará. In: Anais da VIII Semana de Pesquisa da Fundacentro; 2008; São Paulo. p. 141-148. [acessado em 2014 maio 29]. Disponível em: http://www.fundacentro.gov.br/ arquivos/cursos-e-eventos/semana-da-pesquisa/2008/ anais-semana-da-pesquisa-2008-completo.pdf.

25. Rosa MFM, Mattos UAO. A saúde e os riscos dos pescadores e catadores de caranguejo da Baía de Guanabara. Cien Saude Colet 2010; 15(1):543-1552.

26. Barbosa SRCS. Identidade social e dores da alma entre pescadores artesanais em Itaipu, RJ. Ambient Soc 2004; 7(1):107-131.

27. Mello AF. Movimentos sociais na pesca. Boletim do Museu Paraense Emílio Goeldi 1995; 11(1):19-39.

28. Brasil. Lei $n^{\circ} 11.699$, de 13 de junho de 2008. Dispõe sobre as Colônias, Federações e Confederação Nacional dos Pescadores, regulamentando o parágrafo único do art. 8 o da Constituição Federal e revoga dispositivo do Decreto-Lei no 221, de 28 de fevereiro de 1967. Diário Oficial da União 2008; 16 jun.

29. Brasil. Constituição da República Federativa do Brasil de 1988. Diário Oficial da União 1988; 5 out.

30. Brasil. Ministério da Saúde (MS). Conselho Nacional de Saúde. Resolução no 196 de 10 de outubro de 1996. Diretrizes e Normas Regulamentadoras de Pesquisas Envolvendo Seres Humanos. Diário Oficial da União 1996; 16 out.

31. Minayo MCS. O desafio do conhecimento: Pesquisa qualitativa em saúde. São Paulo: Hucitec; 1994.

32. Flick W. Uma introdução à pesquisa qualitativa. Porto Alegre: Bookman; 2004.

33. Buss PM, Pellegrini Filho A. A saúde e seus determinantes sociais. Physis 2007; 17(1):77-93.

34. Rodrigues SCA. A Ilha da Madeira que vira carvão: o processo de apropriação de um território na baía de Sepetiba [dissertação]. Rio de Janeiro: Universidade Federal do Rio de Janeiro; 2012.

35. Laurell AC, Noriega M. Processo de produção e saúde: Trabalho e desgaste operário. São Paulo: Hucitec; 1989.

Artigo apresentado em 02/07/2014

Aprovado em 11/07/2014

Versão final apresentada em 15/07/2014 